\title{
DESIGN THINKING AS A METHOD OF IMPROVING COMMUNICATION EFFICACY
}

\author{
Laurie Spitler $^{1}$ and Laura Talbot ${ }^{2}$
}

\begin{abstract}
Construction projects can be framed as a network commitments as defined by Linguistic Action Theory. With each project, varied requirements, designs, stakeholders, personalities, and countless other factors create new, indeterminate sets of issues whose resolution will be unique and determined by the linguistic actions of stakeholders. Because of this complexity, project definition and execution can be classified as "wicked problems", or problems that are undefined in nature and defy a rational solution. "Design Thinking" is a method of creative problem solving that is useful in addressing wicked problems through its use of divergent brainstorming followed by convergent solution development. This paper first uses a case study to demonstrate how one team used Design Thinking to analyze and improve communication between stakeholders, and then proposes how Design Thinking can be added to the lean tool kit as a method of driving continuous improvement.
\end{abstract}

Keywords: Lean construction, computing, mixed reality, template, instructions.

\section{INTRODUCTION}

In the fall of 2016, ten Autodesk volunteers spent two weeks in Kigali, Rwanda, as part of a partnership with a local design firm, MASS Design Group, and the fellows of the African Design Centre. Based in Kigali, the ADC works as a complement to existing architecture and design schools to further students' education through an intensive two-year fellowship program. Autodesk volunteers worked with MASS and ADC to provide software training, make connections with local non-profits, and study communication between MASS Design and local Rwandan builders. The communication study was initially framed as a very simple question: "How can we educate our builders to understand drawings so that less time is spent on construction administration?"

The subsequent exploration of that question led to a realization of the complexity of the problem, and the application of Design Thinking to develop a solution.

By designing solutions with people rather than for them, MASS has demonstrated the value of thoughtful, inclusive design and has recognized that a creative and humancentered approach can improve the lives of the poor. Design programs in sub-Saharan Africa are scarce, and the continent needs a greater force of trained professionals who can help plan, design, and build the future. Training local designers has been central to MASS's architectural work since its launch, and the African Design Centre is a progression of this initiative. MASS Design believes that socially-minded designers, bolstered by entrepreneurial thinking, can multiply access to dignified solutions.

1 Customer Engagement Specialist, Autodesk, San Francisco, CA 94107, USA, +1 415 342-1073, laurie.spitler@autodesk.com

2 Customer Engagement Specialist, Autodesk, San Francisco, CA 94107, USA, +1 415 342-1073, laura.talbo@autodesk.com 
MASS Design's intensively focused human-centered and sustainable approach to project delivery includes the use of local material and labor. The local labor, referred to as "builders" throughout this paper, typically does not have the training or specialization common in more developed building cultures. Additionally, most builders speak only the local dialect, Kinyarwandan. This unfamiliarity with drawing conventions and language has led to amusingly literal interpretations of the drawings. In one instance, a MASS designer witnessed a builder carefully etching a cloud outline into a recently-poured slab of concrete so that it would look like the drawings. In another instance, the builders installed larger stones to mimic the exact scale of a hatch pattern in the drawings, instead of the gravel the hatching was meant to represent. Because of these communication gaps, MASS Design found that they were taking on a degree of site supervision and Construction Administration way beyond what is budgeted for a design firm.

The Autodesk team explored the surface question of educating the builders by applying the Lean technique of the " 5 whys". Among the questions posed were "What about the drawings are hard for the builders to understand?", "What methods have you found that are effective for communication of design intent?", and "What guidance is given during Construction Administration?". The exercise revealed the following:

- MASS Design's drawing standards derive from American Institute of Architects (AIA) guidelines. AIA standards for navigation, detail call outs, clouded changes, symbols and language are problematic for Rwandan builders.

- MASS Design is an innovative architect, using complex design components unfamiliar to local builders, such as trusses with complicated, non-orthogonal connections, new local materials that require experimentation before full detailing, and atypical design details such as trapezoid-shaped windows

From the application of the 5 whys, the team realized that the root issue was a complex issue of communication with many contributing factors. In short, a wicked problem.

\section{BACKGROUND}

With its concern of communication between stakeholders, this paper focuses primarily on the human factors in construction. Flores (1982) captures the importance of the human factor with the statement, "Management is that process of openness, listening, and eliciting commitments, which includes concern for the articulation and activation of the network of commitments, primarily produced through promises and requests, allowing for the autonomy of the productive unit."

Linguistic action theory explores the interactions between individuals on a project and "describes the very human processes, the purposeful ways people communicate, by which projects are conceived and delivered." (Macomber and Howell, 2003) Macomber explores how the Last Planner, commonly understood as a production control system, is supported by linguistic actions, which draw attention to the "conversational nature of design, planning, and coordination."(Macomber et al, 2005) Howell et al (2004) propose a new management model based on a network of commitments, stating "The new role of every project leader ...is to shape circumstances for team members to deepen their relatedness by developing a shared understanding, cultivating commitment-making, and producing coherence of intentions." This paper uses Linguistic Action Theory's understanding of a project as a network of commitments, rather than a project based production system as a conceptual starting point for the case study. 
On a macro scale, Whelton and Ballard (2002) apply the concept of "wicked problems", a term introduced by Horst Rittel, to construction project definition. In one of the first published reports on Rittel's work, wicked problems are described as a "class of social system problems which are ill-formulated, where the information is confusing, where there are many clients and decision makers with conflicting values, and where the ramifications in the whole system are thoroughly confusing" (Buchanan, 1992) Whelton and Ballard present case studies to demonstrate how project definition can be treated as wicked problems, with research that suggests that "greater and timely understanding of stakeholder interests is necessary in order to better manage wicked problems"

The origin of the concept of "wicked problems" lies in design theory. Buchanan (1992), outlines the history and evolution of Design Thinking in the twentieth century as a liberal arts discipline well suited to the nature of wicked problems. Design Thinking is the result of "a concern to connect and integrate useful knowledge from the arts and sciences alike, but in ways that are suited to the problems and purposes of the present." Employing Design Thinking, designers move past concrete categorization of problem definition and use different "placements" or contexts to "position and reposition the problems and issues at hand."

Specific Design Thinking methodologies follow a divergent-convergent model. First, all possible ideas are collected though exercises that systematically solicit stakeholder input, then solutions are developed through rapid iteration and testing. Several organizations have provided tools to supplement the theory of Design Thinking, or human-centered design. ${ }^{4}$ IDEO has developed a design kit to support their three phases of Inspiration, Ideation, and Implementation. ("IDEO Design kit," n.d.) The LUMA Institute has developed a set of 36 methods divided into three phases: looking, understanding, and making. The looking tools are intended to "foster curiosity, empathy, and objectivity." The understanding tools "help to identify patterns, determine priorities, and translate research into actionable insights." The making tools "enable visual expression and iterative improvement." ("Luma Workplace," n.d.)

\section{CASE STUDY}

Both Autodesk and MASS Design apply Design Thinking methodology as part of their corporate identity. Therefore, they chose this technique as a method of setting aside prior biases in information gathering, and developing empathy in the solution finding. Over two weeks, the teams did exercises to (1) observe, (2) understand, (3) prototype, and (4) test. The participants in this study included Autodesk volunteers, MASS Design staff, fellows from the African Design Center (ADC), and builders. The objective of the study was to create and test methods to increase the effectiveness of communication.

\subsection{Observe}

Exercise - Site Visit: The team traveled to Butaro Hospital in the Northern Province to visit several projects completed by MASS Design. As design professionals, MASS architects and the ADC fellows were accustomed to observing and speaking to building

\footnotetext{
3 "Placements are the tools by which a designer intuitively or deliberately shapes a design situation, identifying the views of all participants, the issues which concern them, and the invention that will serve as a working hypothesis for exploration and development. (Buchanan 1992)

${ }^{4}$ For the purposes of this paper the terms "Design Thinking" and "human centered design" will be used interchangeably. There are fine theoretical distinctions between the two terms that will not be addressed.
} 
aesthetics. On this trip, the architects were asked to highlight areas or components of each building that were executed differently than intended by the design and to offer reasons for how the deviation may have occurred. The fellows were asked to identify areas or components of each building that they perceived to be improperly executed. Items identified included:

- Improved joint tolerance in volcanic stone installation from project to project due to the introduction of quality control requirements.

- An odd, oversized foundation that was designed to support a thick wall cladding that was never installed. The cladding was value-engineered out of the project.

To close the visit, the builders were asked to speak to their experience with drawing comprehension, process, and issues that the design team had identified. The builders provided the counterpoint view and insight into their experiences on site.

Exercise -"Build"ing Empathy Workshop: Derived from experiential learning and immersion techniques, this workshop was designed to allow participants to build empathy for the challenges of the builder. As a warm up, the participants were asked to create a list of drawing conventions that are difficult for local builders to comprehend (English text, architectural symbols, etc). Use of the techniques on this list were then disallowed for the duration of the workshop.

The workshop had four parts: Design, Communicate, Build, and Reflect. During the Design phase, each team designed and built a bridge. Next, during the Communicate phase, each group had a set amount of time to create visual instructions to illustrate the bridge design. The Build phase of the exercise asked each team to recreate the other team's design without any guidance, using only the instructions prepared previously. Finally, in the Reflect phase, the teams reflected on the challenges they faced in communicating and interpreting the design intent. (Figure 1)

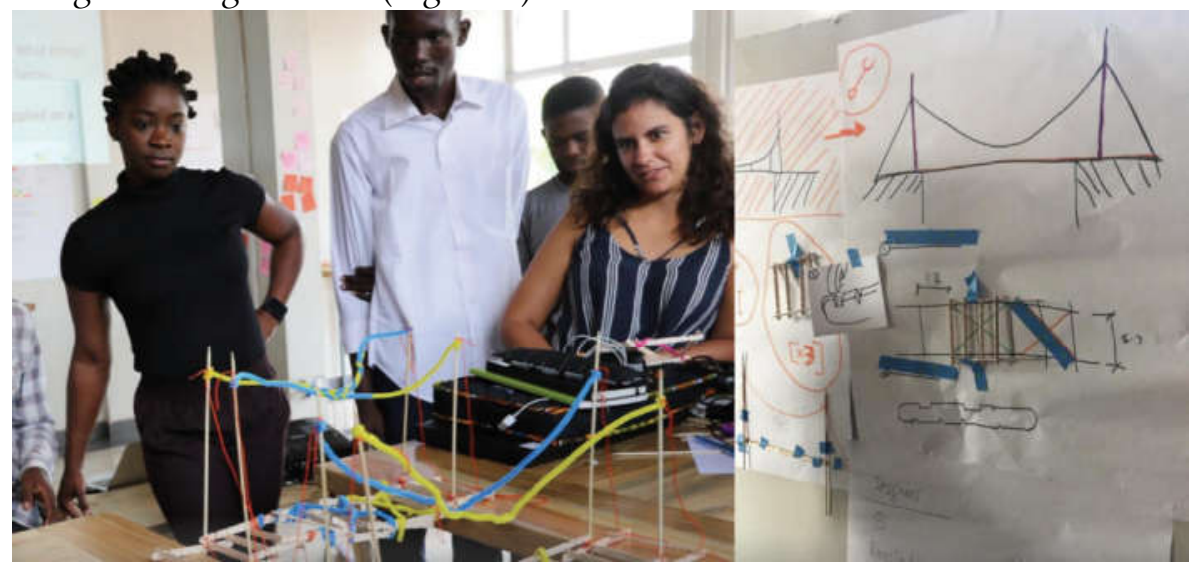

Figure 1: Studying the Results of the Bridge Building Exercise.

\subsection{UNDERSTAND}

Exercise - Thought Organization and Stakeholder Mapping: Following the site visit, the ADC fellows were asked to do a thought organization exercise. Each participant was asked to write positive and negative observations about the design and construction process on post-it notes. The observation post-its were posted and clustered by topic. For example, all observations related to a complex roof support detail and the subsequent cost overruns were grouped together. This exercise allowed for a democratic collection of observations, as all participants contributed regardless of experience or extroversion. 
Next, the fellows were asked to create a project delivery map, spanning from initial idea and community requirements through post occupancy analysis. With each phase of the project identified, stakeholders were added to the map to highlight when each party was (or was not) present, and then add the observed process issues to the map at the point where they manifested, as well as when they might have been mitigated. Invariably, the results revealed that process issues manifested late in the project timeline, with stakeholders different from those involved when the issue might have been mitigated. The exercise identified that more communication was needed between stakeholders throughout the project timeline to mitigate issues related to informational hand-offs and to incorporate lessons learned into the design. (Figure 2)

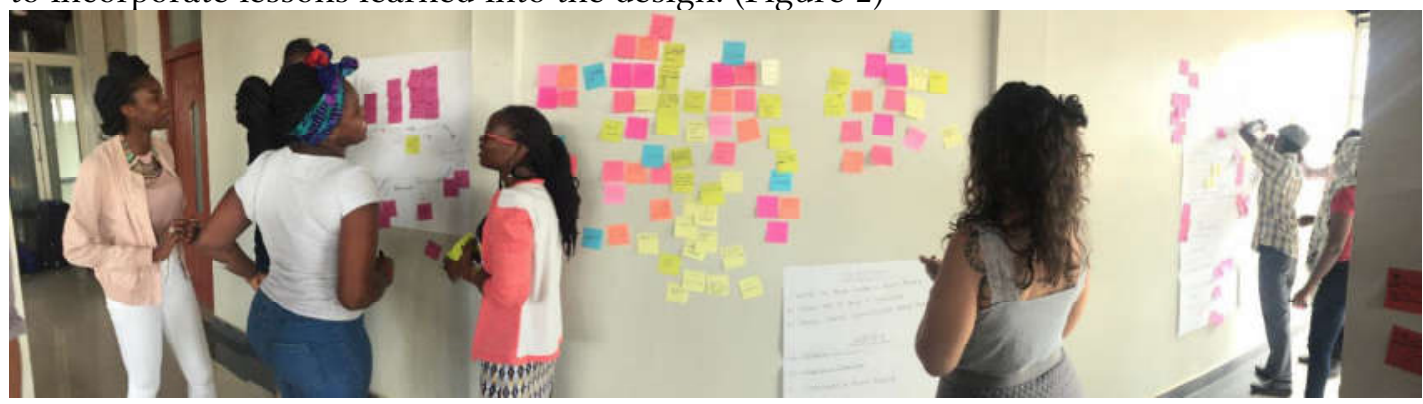

Figure 2: Applying the Thought Organization Exercise to the Stakeholder Maps

\subsection{PROTOTYPE}

After studying the issue of communication between stakeholders through observing and understanding, potential solutions were explored that would target both major stakeholders - in this case, local builders and MASS designers.

Prototype 1 - Design a Training Plan for Builders: One of MASS Design's core missions is to empower the local community. As such, reusable and scalable educational resources for builders should be developed to build experience and create opportunities for future employment. Based on the discovery process, the ADC fellows were asked to prototype a training plan and develop a method of testing the program with the builders.

Prototype 2 - Propose Revised Standards for MASS Design: MASS Design's drawing conventions are based on American standards and were found not to be an effective means of communication for Rwandan builders. Based on the discovery process, the ADC fellows were asked to prototype a set of revised standards and develop a method of testing the program with the builders.

\subsection{TEST}

The teams held a workshop for all participants where the plans were presented:

Prototype 1 - Designing a Training Plan for the Builders: Considering the lessons learning in the prior exercises, the team decided that a simpler set of drawings should be used to illustrate core concepts. The ADC fellows designed a training kit to be distributed on the jobsites. The kit contained a physical model of the building and corresponding drawing set. The model, while simple, could be split in half to show a section and lifted off the foundation to show a plan. The drawing set included plans, sections and details. The intent of this kit was to supplement a lesson in architectural convention for foremen. The lesson would then be relayed by foremen to the builders to perpetuate the learning.

To test this program, the fellows provided the lesson to the builders. Using the model, they demonstrated the concept of plans, sections and details. Following this instruction, 
they asked the builders to draw plans and sections. For many of the builders, this was the first time they had ever produced an architectural drawing. This active learning exercise challenged the builders to think like architects - How are windows detailed? How are door swings visually represented? In short, they demonstrated the importance of symbology in architectural drawing by challenging the builders to produce the representation.

After the drawing exercise, the builders were asked to provide feedback on how the lesson could be improved. The builders felt that they learned from the exercise, and that they would appreciate the opportunity to draw and compare more architectural symbols, such as columns, walls, and doors, in the future. (Figure 3)

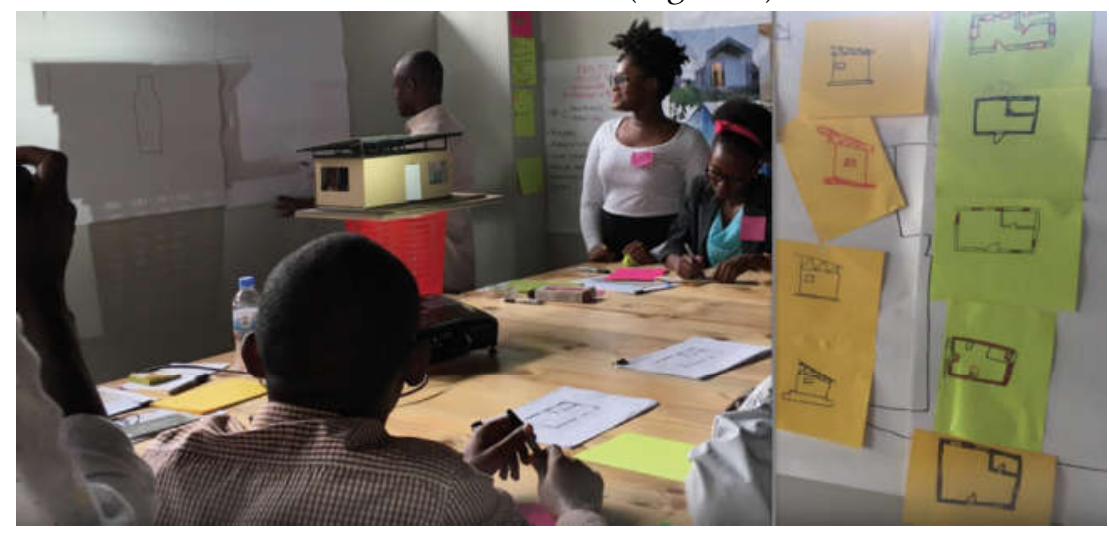

Figure 3: Teaching Builders how to Draw

Prototype 2 - Revised Drawing Standards for MASS Design: It was clear from the site visit and workshop exercises that the complex symbology and organization of the MASS Design drawing sets were not optimal for conveying design intent to the builders.

The ADC fellows developed a framework for drawing standards for building. To test which drawings were most useful to the builders, they produced different types of drawings for wall construction, including a model, a 3D render, an exploded axonometric, a dimensioned plan, a color-coded plan denoting wall types, a section, and details.

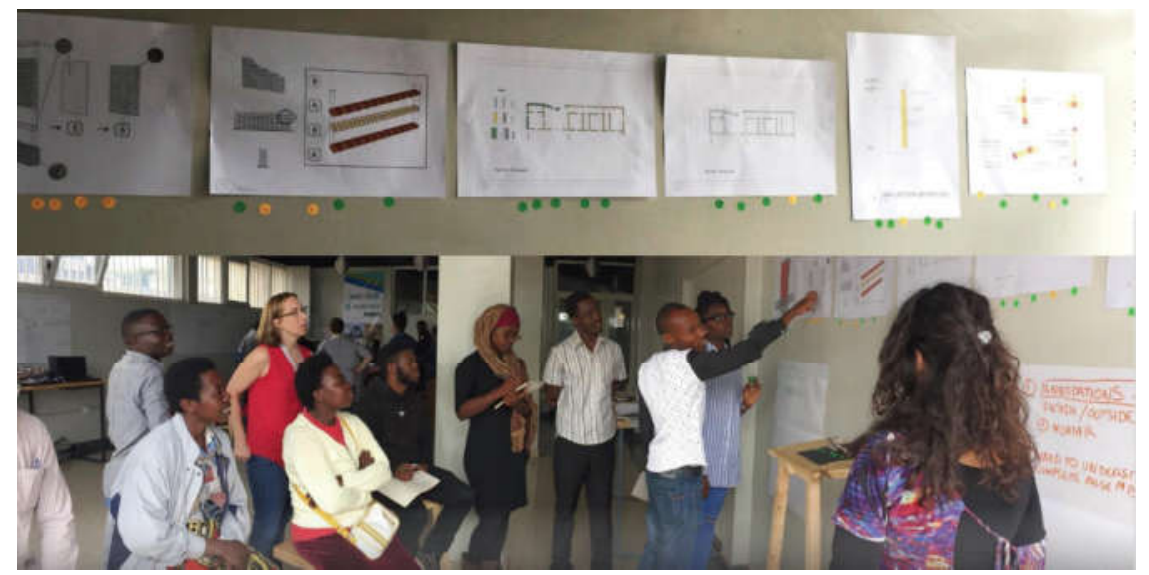

Figure 5: Designers and Builders having a Conversation about Communication

The builders were asked to vote on the drawings, using green stickers for drawings that were clear and orange stickers for drawings that were overly complicated or confusing. Stickers were labeled with the level of the builder (superintendent, foreman, laborer) who had placed the vote. The builders then explained their votes. Some conclusions were 
expected, such as the positive votes on the $3 \mathrm{D}$ rendering, and that the more educated builders found details useful. Other feedback surprised the design team. The builders were confused by an exploded axon, drawn to show the sequence of wall construction, because they "did not understand what was supposed to be put in the gaps" of the drawing. (Figure 5)

\section{DISCUSSION}

The workshop created a space for stakeholders to come together to discuss how to increase communication efficacy. The use of Design Thinking techniques allowed for (1) democratic contribution of information and (2) empathy building between stakeholders.

The democratic contribution of information was facilitated through exercises such as thought organizing. By asking all members of the team to submit ideas though notes on post-its and vote with stickers, the team mitigates the possibility of submissions being ranked on seniority, extroversion, or other persona-based criteria. By including team members with a variety of roles and perspectives, a diversity of contributions is guaranteed. Hence, these techniques allow for the widest base of knowledge and ideas to be included in the problem definition and solution phase.

Empathy was built for other stakeholders through the series of exercises that asked the team to experience the project though other's perspectives. At the site visit, both the designers and the builders were given uninterrupted time to speak to their experiences. In the bridge building exercise, designers were asked to work with the restrictions of the builder. The builders were asked to draw architectural drawings as a method of learning. Through these exercises, the stakeholders experienced the constraints and motivations of the other party. Because of the study, the designers realized that in addition to educating the builders, they could also learn from the builders' experience to improve design communication efficacy. Additionally, through the repeated non-hierarchical interactions, a sense of community and collective purpose was fostered.

The techniques outlined in this paper are applicable beyond the somewhat extreme example of design and building in Rwanda. Design Thinking exercises bear striking similarities to Lean techniques - most notably, pull planning. In both exercises, input is solicited in a democratic manner and stakeholders are asked to work together to build a collective plan to execute and evaluate. Design Thinking provides methods to apply this type of collective and creative problem solving to other aspects of project delivery.

As Whelton and Ballard (2002) have stated, project definition is a wicked problem: illdefined and non-repeatable. Design Thinking is a discipline that explicitly address the indeterminate nature of wicked problems by drawing on multiple contexts to frame the problem and optimize solutions. No project or process is repeatable as stakeholders, project type, and contractual relationships change. Design Thinking can be applied in broad and focused ways as a systematic method of process analysis and continuous improvement. To identify project level improvements:

- Trade partners could collectively identify and cluster risk areas based on past experiences. The team could collectively agree on controls such as focused BIM coordination, design modifications, or others to mitigate identified risk.

- The team can map out a process that involves multiple stakeholders, do immersion exercises to understand motivations, and then propose process improvements.

As the case study demonstrated, beyond specific process improvements, the nature of the exercises will allow stakeholders to become more knowledgeable of the holistic project 
and more empathetic with other stakeholders. Design Thinking can also be applied as a targeted to solution, such as:

- If a root cause of task failure is occurring with undue frequency, the stakeholders can complete a thought organization exercise to generate resolution

- To identify communication issues within a team and then process map a solution.

\section{CONCLUSION}

Given the understanding of a project as a "network of commitments" (Howell et al, 2014), projects need to develop corresponding tools to address and manage the human process. This paper has demonstrated how Design Thinking can be applied to the wicked problems that occur in project delivery. The case study demonstrates how the use of Design Thinking allowed a team to (1) democratically generate ideas to increase the efficacy of communication between stakeholders and (2) develop an empathetic solution suited to the motivations of each stakeholder. The paper also proposes other areas in project delivery to apply Design Thinking methodology. As such, Design Thinking should be added to a project's Lean toolkit as a method of driving continuous improvement.

\section{REFERENCES}

Buchanan, R. (1992). Wicked problems in Design Thinking. Design Issues, 8(2), 5. doi:10.2307/1511637

Flores, F., (1982). Management and Communication in the Office of the Future, PhD Dissertation, University of California at Berkeley, p.42.

Howell, G. A., Macomber, H., Koskela, L., and Draper, J. (2004). "Leadership and Project Management -- Time for a Shift from Fayol to Flores.” Proc. 12th Annual Conference of the International Group for Lean Construction Elsinore, Denmark, 8 pp.

IDEO Design kit. (n.d.). Retrieved from http://www.designkit.org/

Luma Workplace. (n.d.). Retrieved from https://www.lumaworkplace.com/

Macomber, H. \& Howell, G.A. 2003, 'Linguistic Action: Contributing to the Theory of Lean Construction' In:, 11th Annual Conference of the International Group for Lean Construction. Virginia, USA, 1-.

Macomber, H. , Howell, G.A. \& Reed, D. 2005, 'Managing Promises With the Last Planner System: Closing in on Uninterrupted Flow' In:, 13th Annual Conference of the International Group for Lean Construction. Sydney, Australia, 19-21 Jul 2005. pp 1318

Whelton, M. \& Ballard, G. 2002, 'Project Definition and Wicked Problems' In:, Formoso, C.T. \& Ballard, G., 10th Annual Conference of the International Group for Lean Construction. Gramado, Brazil, 6-8 Aug 2002. pp 375-387 